\title{
Evaluation of Fracture Healing Property of Ethanolic Extract of Cissus quadrangularis Using 3-Point Bending Model in Rats
}

\author{
Reena R. Giri ${ }^{1}$, Kiran R. Giri ${ }^{2 *}$ and Kamlesh Palandurkar ${ }^{3}$ \\ ${ }^{1}$ Department of Pharmacology, RIMS, Rajnandgaon C.G., India \\ ${ }^{2}$ Department of Pharmacology, ${ }^{3}$ Department of Biochemistry, BHU, Varanasi, India \\ *Corresponding author
}

\section{A B S T R A C T}

\section{Keywords}

Closed

transverse

Fracture,

Skiagram.

Article Info

Accepted:

26 May 2017

Available Online:

10 June 2017
A study was undertaken to evaluate the fracture healing effect of ethanolic extracts of Cissus quadrangularis on experimentally fractured tibia of rats radiologically by using 3-point bending model. Closed transverse fracture of the mid - diaphysis of left tibia were created in rats after Phenobarbitone \& Ketamine anaesthesia, by 3- point bending method. In the skiagram there was an evidence of union in Cissus quadrangularis treated group with extensive bony deposition compared to that of control [Normal saline] group. In our study, the findings assessed on the basis of radiological studies showed that ethanolic extract of Cissus quadrangularis had a definite fracture healing effect. The extracts can also be utilized as a new source of bone healer in the treatment of fracture.

\section{Introduction}

Bone is a very active tissue and that any injury to it will induce a series of biological and biochemical changes (Udupa et al., 1964).

The chemical analysis of Cissus quadrangularis revealed a high concentration of vitamin $\mathrm{C}$, carotene $\mathrm{A}$, a substance like anabolic steroid and calcium.

It has been known for long time for its specific action on fracture healing (Udupa et al., 1964; 1960), hence selected for observation of its actual effect on the process of fracture healing judged by radiological examination in experimental animals (rats).

\section{Materials and Methods}

The present study was conducted after the approval of research protocol by the Institutional Animal Ethical Committee, Jawaharlal Nehru Medical College, Sawangi (Meghe), Wardha. Cissus quadrangularis purchased from local herbarium Nagpur", identified and authenticated with the standard sample preserved as Cissus quadrangularis, by Botany Department, R. T. M. University Nagpur. The fleshy stems of CQ washed and cut into small pieces, air dried. Then $4 \mathrm{~kg}$ of chopped pieces of Cissus quadrangularis was soaked in $6 \mathrm{~L}$ of Ethyl Alcohol $99.9 \%$ for 48 $\mathrm{h}$, and the extract was filtered and allowed to air dry. 
The total ethanol extract was concentrated in vacuo till a syrupy consistency is obtained. For administration, the extract was suspended in distilled water. Preliminary phytochemical studies of extracts done using standard procedure at Laboratory of Department of Pharmacognosy, R. T. M. Nagpur University, and Nagpur which shows the presence of Flavones, Saponins, Glycoloides, in the extract.

\section{Experimental Animals}

The study was conducted using 16 Wistar Albino Rats, of either sex weighing 150-200g obtained from Institute of Pharmaceutical Education and Research Borgaon (Meghe), Wardha.

Animals were acclimatized on standard nutritional and environmental condition in separate cages and fed with standard laboratory chow and provided with water $a d$ libitum.

Before surgery every rat was subjected to clinical orthopedic evaluation and dorsopalmar radiographic views of the left tibia were obtained $(40 \mathrm{kV} / 32 \mathrm{mAs}$ and $0.26 \mathrm{~s})$ (Antti, 2002).

Animals were anaesthetized with Phenobarbitone $60 \mathrm{mg} / \mathrm{kg}$, IP and Ketamine [Anikate, $40 \mathrm{mg} / \mathrm{kg}$, IP]. Then closed transverse fracture of the mid - diaphysis of left tibia were created in rats by three point bending method (Chuanyong et al., 2006).

The bone was positioned horizontally with the anterior surface upwards. The pressing force was directed vertically to the midshaft of the bone. Each bone was compressed with a constant speed and compression force. These fractured limbs were stabilized with splints after reduction and animals were allowed to move freely after recovering from anesthesia.

\section{Grouping of animals}

Animals were divided into 2 groups of eight animals each.

Group I $\quad$ - $\quad$ Normal saline (NS) (2 $\mathrm{ml} / \mathrm{kg}$ ) orally for 30 days.

Group II - Cissus quadrangularis (CQ) orally (500mg/kg body weight) o. d, for 30 days.

\section{Preparation of working solution}

The required amount of syrupy extract of Cissus quadrangularis measured as per the dose/bodyweight $(500 \mathrm{mg} / \mathrm{kg})$ of rats and daily fresh solution used to made with distilled water $(2 \mathrm{ml})$

\section{Radiological evaluation}

The animals were evaluated clinically every day to determine general condition and lameness. Lameness was evaluated by observing each animal moving freely in the cage. Bone healing of NS group and drug treated groups was followed in each animal by radiographic evaluation immediately after surgery and every week thereafter for 4 weeks using the same technique. The left tibiae were placed in a standard lateral position over Kodak Lanex Single Screen. Radiographs were exposed on Kodak Min-R film with $40 \mathrm{kV} / 32 \mathrm{mAs}$. The visibility of the fracture line was observed and scored as totally visible, partly visible, or absent.

Qualitative assessment included fracture line/margins, fracture gap, external callus appearance, bridging, and radiologic union done by radiographic evaluation. (Range of radiation maintained as per Potter who had demonstrated a relationship between exit dose and lethality in rats with 100 and 400kvp.) ${ }^{[5]}$ 


\section{Results and Discussion}

Radiological findings taken at weekly intervals.

$\mathbf{1}^{\text {st }}$ week

$\mathrm{X}$-ray did not reveal any marked difference in the various groups [CQ, NS]. The fragments were freely mobile. Broken ends were still visible on x-ray. This is a fibroblastic phase [Plate 1 (1.I, 1.II)].

$2^{\text {nd }}$ week

The skiagram showed beginning of callus formation and bridging of gap in CQ treated group but no such results observed in NS treated group, there the gap was still visible. Mobility of fragments still present to certain extent [Plate 2 (2.I, 2.II)].

$3^{\text {rd }}$ week
The X-ray showed greater amount of calcification of callus in CQ treated group in which one could hardly see a gap at the fracture site, fragments could not be elicited whereas in NS group some gap was still visible. This is an osteogenic phase [Plate 3 (3.I, 3.II)].

$4^{\text {th }}$ week

In the skiagram there was an evidence of union in CQ group. Almost complete bridging of the fracture ends with extensive bony deposition compared to that of control [Normal saline] group is seen in CQ treated group. This is also an osteogenic phase [Plate 4 (4.I, 4.II)].

\section{Radiological findings $1^{\text {st }}$ week after fracture healing}

(Plate 1.I) Cissus quadrangularis

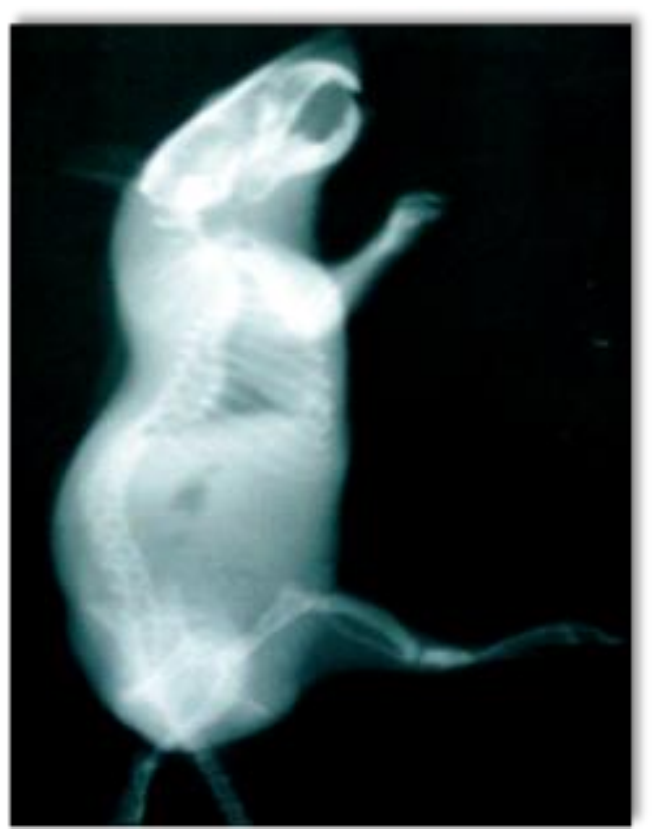


(Plate 1.II) Normal saline

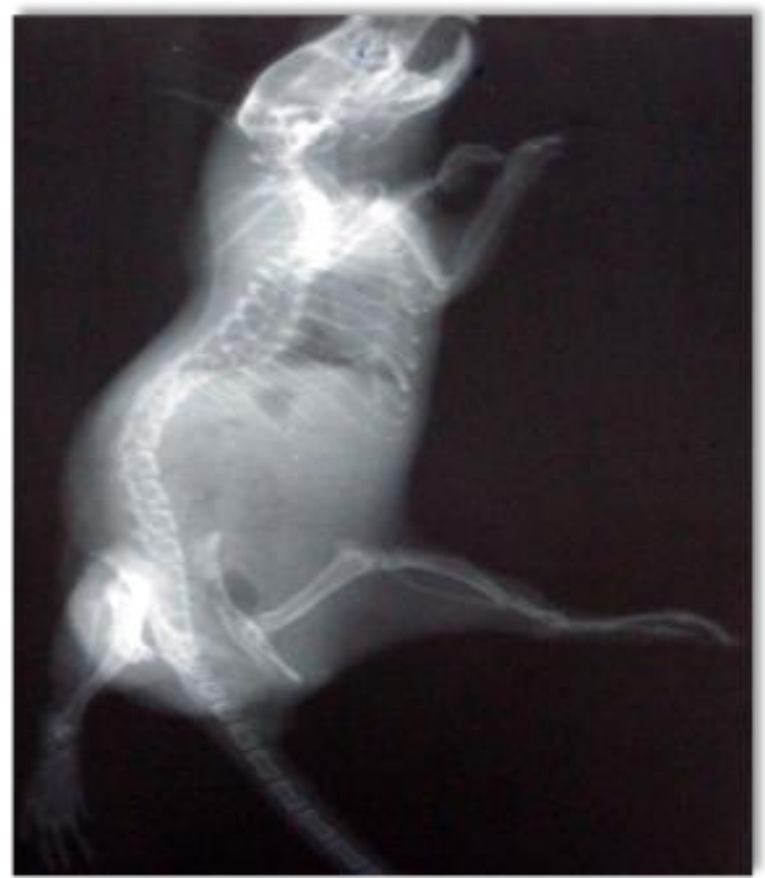

Radiological findings $2^{\text {nd }}$ week after fracture healing

(Plate 2.I) Cissus quadrangularis

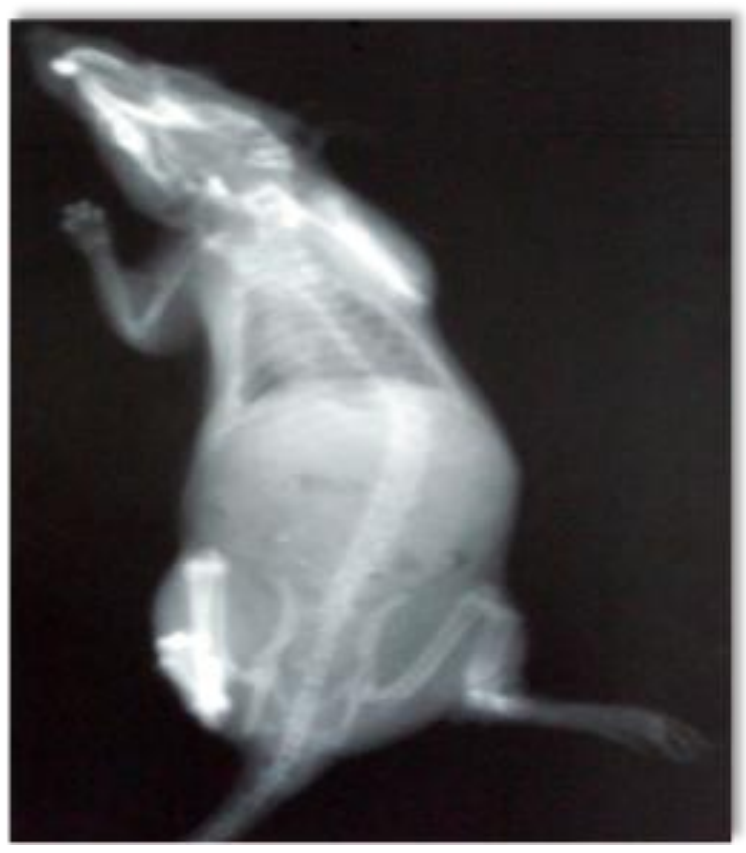


(Plate 2.II) Normal saline

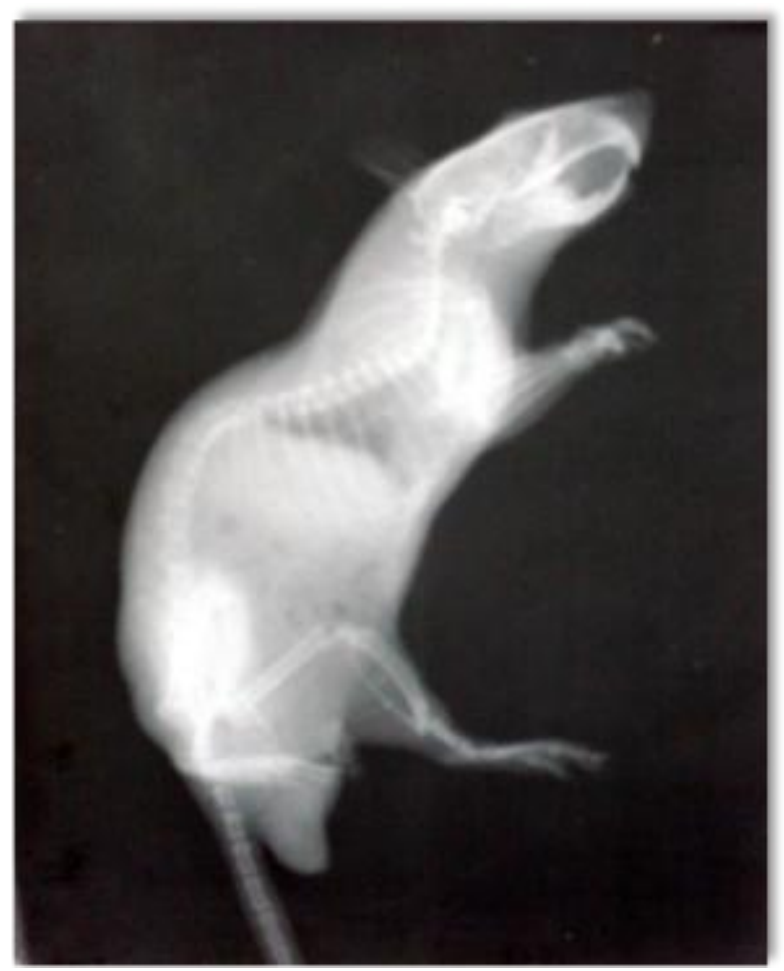

Radiological findings $3^{\text {rd }}$ week after fracture healing

(Plate 3.I) Cissus quadrangularis

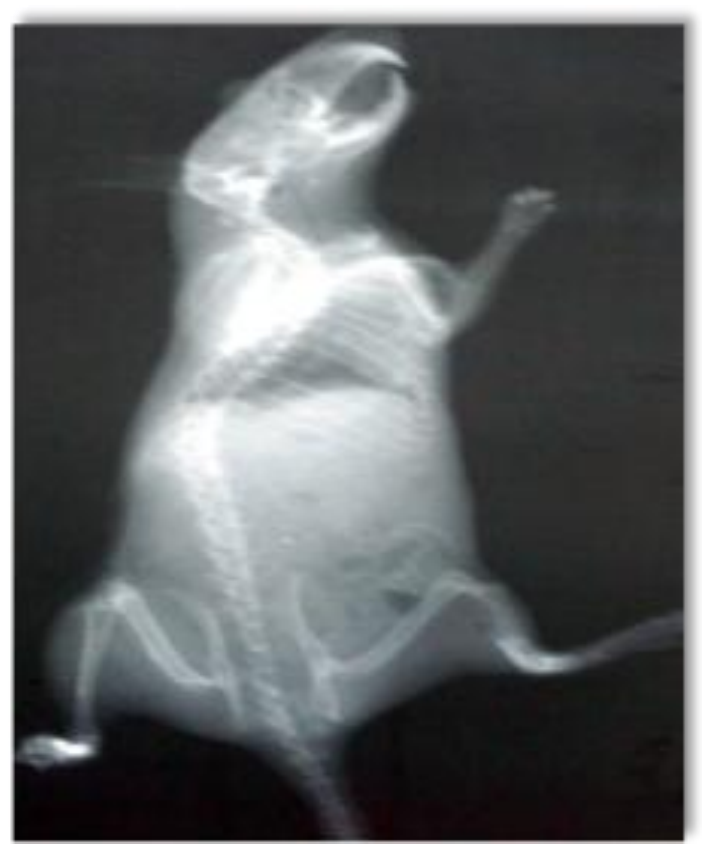


(Plate 3.II) Normal saline

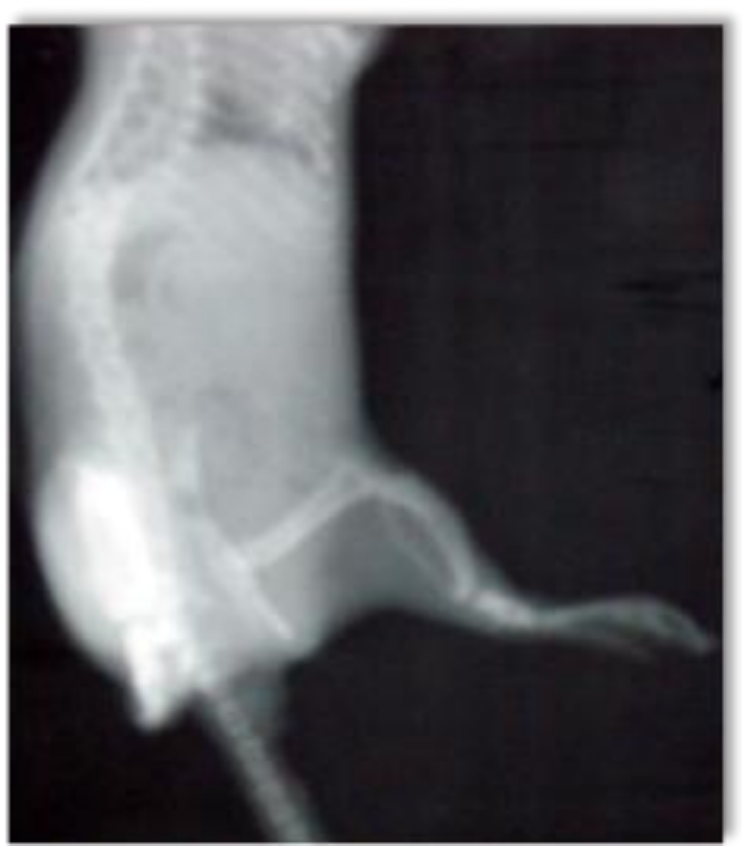

Radiological findings $4^{\text {th }}$ week after fracture healing

(Plate 4.I) Cissus quadrangularis

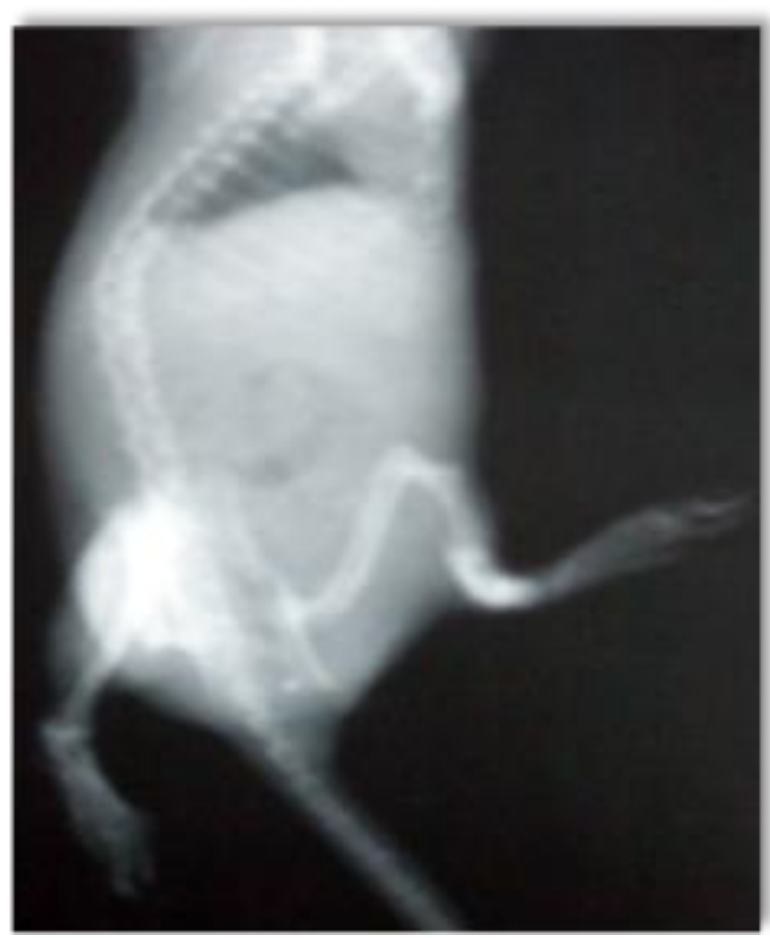


(Plate 4.II) Normal saline

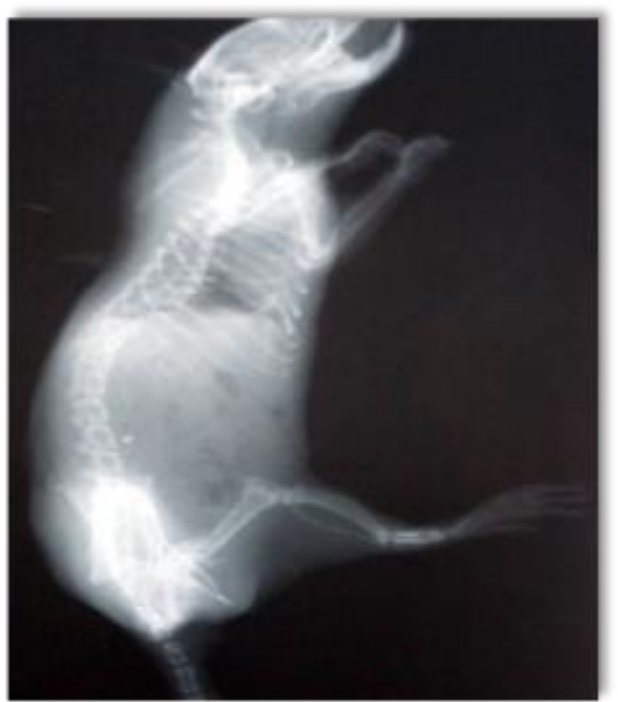

It is well known since many centuries to the indigenous medical practitioners and also to the people working in jungles that a paste prepared from the herb CQ applied to the injured limbs greatly helps in the healing of fractures. Further it was tried for internal use by way of drinking decoction prepared by boiling the fresh herb in milk. This indicated that the active principle might be a fat soluble substance. Hence we prepared alcoholic extract for use in animals.

Radiography is an established method for evaluating fracture healing both in clinical use and in animal studies. Radiographs are able to visualize callus formation after mineralization (Aronson et al., 1994; Kato et al., 1998; Reichel et al., 1998).

Radiological findings in the present study demonstrated that, in both the groups during first week there was no evidence of callus formation and the fragments were freely mobile.

During $3^{\text {rd }}$ and $4^{\text {th }}$ weeks the callus progressively became harder and the movement between fragments could not be elicited in the herb treated group. Our results are in conformity to those found in the study of Guru Charan Prasad and Udupa, 1963. At fourth week of fracture radiograph of the CQ treated group revealed almost complete bridging of the fracture ends with extensive bony deposition and periosteal reaction in contrast to that of normal saline treated group. Ham, 1974 also demonstrated similar radiographic evidence of early periosteal reaction and bony dissolution in the Cissus quadrangularis treated animals (Bos et al., 1983).

Our study indicates that daily administration of an alcoholic extract of Cissus quadrangularis orally in the dosage of $500 \mathrm{mg} / \mathrm{kg}$ seems to have definite action on the rate of healing of fractures. The active principles responsible for the fracture healing property of Cissus quadrangularis need to be investigated further to elucidated the precise modus operandus of this herb. Proposition to administer Cissus quadrangularis deserved to be explored in depth for defining its place in the overall management of fracture healing.

\section{Acknowledgement}

Heartfelt gratitude to Mr. Rajaram A. Hire for his kind support in performing experiment and throughout research work. 


\section{References}

Antti Koivukangas. 2002. Effects of longterm clodronate administration on bone and on fracture healing in rat, with special reference to methodological aspects; Division of Orthopaedic and Trauma Surgery, University of Oulu. Chapter, 1-6.

Aronson, J., Shen, X. 1994. Experimental healing of distraction osteogenesis comparing metaphyseal with diaphyseal sites. Clin. Orthop., 25-30.

Bos, G.D., Goldberg, V.M., Powell, A.E., Heiple, K.G. and Zika, J.M. 1983. The effect of histocompatibility matching on canine frozen bone allografts. J. Bone Joint Surg. Am., 65: 89-96.

Chuanyong Lu, et al. 2006. assessing angiogenesis during fracture healing. Iowa Orthop. J., 26: 17-26.

Douglas Grahn, et al. 1956. Comparative effectiveness of several X-Ray qualities for acute lethality in mice and Rabbits; Radiation Res., 4: 228-242.
Guru Charan Prasad, Udupa, K.N. 1964. Effect of Cissus Quadragularis on the healing of cortisone treated fracture. Ind. J. Med. Res., 51: 667-676.

Kato, T., Kawaguchi, H., Hanada, K., Aoyama, I., Hiyama, Y., et al. 1998. Single local injection of recombinant fibroblast growth factor-2 stimulates healing of segmental bone defects in rabbits. J. Orthop. Res., 16: 654-659.

Reichel, H., Lebek, S., Alter, C. and Hein, W. 1998. Biomechanical and densitometric bone properties after callus distraction in sheep. Clin. Orthop., 237-246.

Udupa, K.N., Arnikar, H.J., Singh, L.M. 1960. Experimental studies of the use of Cissus quadrangularis in healing of fracture. The Indian J. Med. Sci., 551557.

Udupa, K.N., Guru Charan Prasad. 1964. Further studies on the effect of CQ in accelerating fracture healing. Ind. $J$. Med. Res., 52(1): 26-34.

\section{How to cite this article:}

Reena R. Giri, Kiran R. Giri and Kamlesh Palandurkar. 2017. Evaluation of Fracture Healing Property of Ethanolic Extract of Cissus quadrangularis Using 3-Point Bending Model in Rats. Int.J.Curr.Microbiol.App.Sci. 6(6): 2924-2931. doi: https://doi.org/10.20546/ijcmas.2017.606.347 